\title{
Predicting Financial Crises: Draw Probabilities as Leading Indicators
}

\author{
By Zeyu Jin* \\ Demos Vardiabasis ${ }^{\dagger}$ \\ Samuel Seaman
}

\begin{abstract}
This paper explores the use of sequential draw probabilities for two "players", banking and enterprise sectors, to predict impending financial crisis. Financial crises typically follow cyclical patterns where positive and negative turns are generated by underlying economic mechanisms. We envisage risk transfer between the financial sector and the real economy as one such mechanism. An analysis of draw probabilities calculated for differences in essential measures of fiscal risk, from the banking and enterprise sectors, reveals a intriguing phenomenon that may be used to assess the proximity (or remoteness) and possible intensity of financial crisis. Specifically, we provide evidence that draw probabilities comparing the competitive differences in Return of Equity between banks and enterprises, can be helpful in gauging asymmetry of risk; where such asymmetry has, historically, preceded grim financial outcomes.
\end{abstract}

Keywords: Draw probabilities, Financial crisis, Risk analysis.

\section{Introduction}

Banks originate loans to finance the capital projects of enterprises across the real economy. The Return on Equity (ROE) realized by the borrower should not be too different from the return on bank capital used for funding those projects. We further assume that realized rates of return on funding sources delivered by banks should be consistent with the rates of return on other tangible and financial resources used to finance the project. On average, $\mathrm{ROE}$ in the real sectors of the economy approaches some nominal level, which in a stable and balanced economy cannot be much lower than the bank's rate of return on capital. On the other hand, if the ROE for enterprise projects is far less than rate of return on capital, one might wonder about the extraordinary "gain" for the bank where there is no justification, based upon the risk and return trade-off principle. Or, this unjustifiable difference in returns could imply an increasing risk amongst banks, which had not been reflected in real returns on the projects in the economy.

We have created an explicit metric (a draw probability) based on this difference in ROEs and established a "normal standard" for the magnitude of this metric in good economic times, that offer warning of imminent financial crisis.

\footnotetext{
${ }^{*}$ PhD Student in Economics, Stanford University, USA.

${ }^{\dagger}$ Professor of Economics, Pepperdine University, USA.

${ }^{\star}$ Professor of Decision Science, Pepperdine University, USA.
} 
Estimation of the differences in returns will be related to factors reflective of the trade-off between risk $(\sigma)$ and return (ROE). In this paper, we consider the following metrics to fully characterize these differences: BROE/EROE, $\mathrm{BROE} / \sigma_{\mathrm{BROE}}, \mathrm{EROE} / \sigma_{\mathrm{EROE}}, \sigma_{\mathrm{BROE}} / \sigma_{\mathrm{EROE}}$. All metrics have been calculated using data from financial reports, for banks and companies in the USA economy, included in the Wharton Data Base.

\section{Modeling Financial Cycles}

Business cycles are expected with economic development in any society, begging for proposed theories of the mechanisms of business cycles and economic growth. An important consideration in macroeconomics is, of course, national income (GDP), along with the growth and fluctuations in GDP, over time. Variations in GDP are reflected in business cycles which occur in the short term, yet economic growth ought to be observed over a much longer horizon. Financial crises are related to developments in the economy and the cyclical nature of that development, with several types of business cycles. In the mid-20th century, Schumpeter and others proposed a typology of business cycles according to the observed periodicity; the Kitchin inventory cycle of 3-5 years, the Juglar fixed investment cycle of 7-11 years, the Kuznets infrastructural investment cycle of 1525 years and the Kondratiev wave or long technological cycle of 45-60 years. The patterns of these cycles are not regular and cannot be reflected by any specific mathematical formulae.

Business cycles are, however, consistent with the complexion of the economy. They are like seasons and cycles in the biological growth and development of human-beings. The fundamental difference between the seasons of life and business cycles can be found in their fundamental motivations. The seasons are nurtured by the laws of nature, including the laws of physics, whereas business cycles are cultivated by the behavior of human beings. The economy and economic laws are integrated with the human experience.

Some theories from the past have attempted to explain patterns of economic development using data amassed from the aggregated results of all business entities (Mendoza and Terrones 2012). This approach has been embraced using exogenous models, focused on outcomes of business-unit activity rather than the fundamentals and developmental sources within each economic entity. Other models, called endogenous models, have attempted to explain the effects via certain "causes". These, have considered the fundamental factors and drivers of a company's development as sources of the macroeconomic growth.

There are many growth models based on exogenous factors (i.e. productivity, capital accumulation, population growth and technological progress). We have observed increasing interest in models which help to explain the growth and sources of business cycles using the endogenous (within the enterprise) factors, including, investment in human capital, innovation and knowledge. Shumpeter developed a theory to explain the cyclicality and growth in the economy based on the "creative destruction" of the entrepreneurship activities arising within an organization. These new entrepreneur-creative-innovation models resulted in new 
products and new technology, leading to diminished value of previously existing assets and a decline in the market value of affected companies. This "creative destruction" process, if taken on a grander scale across many branches, has led to major disturbances that have eventually culminated in serious crisis. The consequences of "creative destruction" have been interpreted by Schumpeter as a cost of doing business - something that could not be avoided due to nature of the capitalistic creativity generated by entrepreneur-innovative forces within the enterprise.

Over the last decades in real economy sectors, companies have learned much about the importance of flexibility and the necessity for continuous change through ongoing disinvestments in certain types of "capital" in favor of new forms of investment - due to the pressures of entrepreneur-innovative force. Over the long term, this approach has helped to avoid the calamity triggered in economic sectors. Surprisingly, the newest "attacks" have come from the least expected source - the financial sector. For example, in spite of serious complications that should have served as warning of impending destructive phenomena (i.e. the financial crisis in Asia), markets paid little attention, imagining that these global disturbances would be unrelated in more local economies.

Globalization, population growth and technological progress have created unpredictable conditions economies, challenges for scientists and policy analysts alike; forcing them to adjust their approaches using rational models of business cycles and economic growth. The creation of new models and theories should help explain not only the causes and consequences of short-run fluctuations in GDP or understand the determinants of long-run economic growth, but can also assist decision makers in government and enterprises with tools to create appropriate policies and create adequate business strategies.

Financial stress is inextricably linked to economic development and economic cycles, which are further characterized by different levels of "financial tension". This financial stress has significant impact on the economy and would be useful to define the financial cycles and monitor their characteristics against such economic cycles. Hyman Minsky proposed an explanation of one mechanism leading to financial crisis, which then triggers total economic crisis. Others have proposed alternative models for analysis of financial cycles using certain economic indicators including downturns and upturns in credit, house prices and equity prices (Claessens et al. 2011, Darrell 2011, Jajuga and Krysiak 2005, Mendoza and Terrones 2012). Economic cycles are measured as change in GDP over time. We propose that financial cycles can be characterized by the differences in certain financial metrics: differences between the returns on equity, differences between the volatilities and differences between the returns on equity to volatility ratios, as measured for financial and enterprise sectors. The combination of the three curves derived from the above mentioned measures will be referred to as the Pattern of Financial Cycles (PFC). The analysis of the financial cycle helps to recognize the intensity of financial stress and its proximity to the financial crisis, which may be understood as the most severe phase of the financial cycle.

Modeling the financial cycle will take on greater importance over time, as there is rapid increase in the nominal value of the assets in banking sector due to 
increasing populations, increasing debt per capita and increasing states' budget debts in nominal terms - all in relation to the GDP. The value of debt to the GDP in USA, including social responsibility approaches $100 \%$. In many European countries this ratio greatly exceeds $100 \%$ and it is very likely that it will increase further. For these reasons, there is a need for methods and measures to evaluate the intensity of crisis (Smith and Michaelson 2006, Williams 2010, Wright 2010).

\section{Modeling Risk Asymmetry Reflected in the NASDAQ Bank Index}

Historically, we have observed that specific events tend to precede financial crisis. Before the crisis of 1998-2001, for example, financial institutions were chasing unrealistic returns and exploiting a nascent derivative market. And then, prior to the crisis of 2007-2009 we observed unprecedented growth in the mortgage backed securities market with a hunger for derivatives of a different sort, leading to an unrealistic escalation in real estate prices and a glut of funding sources in the USA. Presently, we observe high growth in the Debt/GDP ratio, particularly in Europe (100\% or higher in many countries), another unique but telling indicator associated with past crises.

It appears that economic calamity in one part of the world can lead to undesirable consequences in financial markets across the globe. Reflecting on economic trends in Europe over the past year or so, we see a recurring pattern in certain indicators that may provide early warning of financial stress. We believe that these indicators might again suggest a troubled future for financial markets and we propose a model that might be useful in predicting such peril. Historical evidence suggests that volatility is a helpful, oft-used indicator of financial risk, but one that may be misleading if not measured within an appropriate contextual framework, controlling for other concomitant metrics. Using the NASDAQ Bank Index, we have identified and calculated three indicators of financial risk: rate-ofreturn, volatility and a rate-of-return to volatility ratio. Based upon these indicators, we will recommend a model for assessing proximity of financial crisis.

Interest in forecasting financial crisis is not a new phenomenon and yet, the crisis of 2007 seems to have laid bare the tragedy of disregard for "modeling" historic data to assess financial stress. While many victims of the crisis look for someone to blame, we believe that the misfortune offers a great opportunity to learn from recent history so that we might avoid future crises. Could the markets, for example, have avoided many of the problems of 2007 if only they had studied, carefully, previous crises around the globe?

A financial crisis in the late 1990's exploded on a global scale, first in Asia, where a contributing factor was the underestimated need for capital in many hedge funds; hedge funds designed to protect banks from incurred losses. The insufficient allocation of capital to hedge funds was likely due to overconfidence in the use of "volatility" as a factor in modeling the demand for capital in financial institutions.

Soon after the crisis in Asia, problems emerged in Russian markets as well and then in 1998 the Long-Term Capital Management (LTCM) hedge fund failed here in the states. The LTCM total balance sheet and off-balance sheet 
financial instruments were approaching about \$1.4 trillion in value. Again, models relying on volatility as a primary indicator of risk for the capital management of this hedge fund proved unreliable. Finally, the last victim of the crisis of the late 90's, Argentina, suffered significantly when its banks, both domestic and foreign experienced deficiencies in capital management as well. Interestingly, the LTCM was, at that time, providing financial services for and cooperating with many financial institutions listed on the New York Stock Exchange, some of which failed during the financial crisis in 2007-2009.

Some analysts anticipate financial crisis by observing recent economic or political events and their corresponding effects on volatility in the Dow Jones Industrial Average and other market indices. Whilst the volatility of stock market indices can be used to measure risk and evaluate conditions in capital and financial markets, even the economy itself, we have observed that volatility alone has, historically, been an unreliable predictor of economic crisis. Volatility in the stock market indices has much greater value when viewed in relation to other measures including rate-of-return and rate-of-return to the volatility ratio. The volatility of rate-of-return in capital markets represents the risk which is associated not only with the particular business or stock but can also be related to current developments in the economy as a whole.

The volatility, rate-of-return and rate-of-return to volatility ratio for the NASDAQ Bank Index are presented in Figure 1. The measures presented are referred to as moving averages, meaning that they filter out noise, leading to a clearer picture of the true trends in the indicators.

Figure 1. Volatility, Return on Equity and Return/Volatility for NASDAQ Bank Index

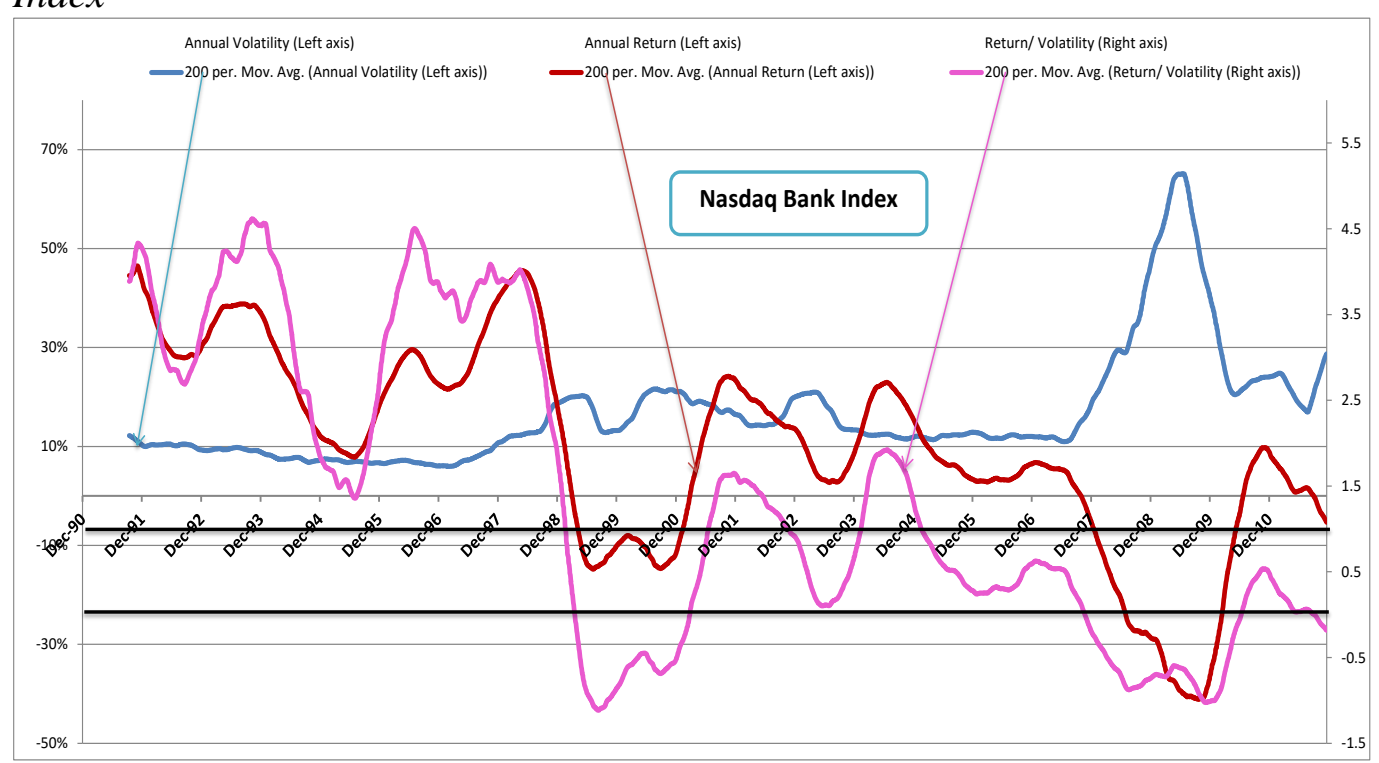

Source: Authors' estimations.

These three measures used together, appear to be reasonably accurate predictors of periods with high likelihood of financial distress. Observing the graphic, for example, one can see that during a crisis event, the rate-of-return to 
volatility ratio is negative whilst in the period immediately preceding the crisis event, the rate-of-return to volatility ratio is quite large. This suggests that for each unit of assumed risk the rate-of-return is unrealistically excessive.

In the past crisis, the rate-of-return to volatility ratio assumed negative values and yet volatility was quite high. The rate-of-return is a reward for assuming risk which is expressed in the volatility. This volatility reflects confidence amongst investors in the expected earnings promised by the enterprise. Laws of economics imply that the greater the risk, the greater the return. However, there is likely some rational and realistic upper limit to the application of this rule.

Rates-of-return well in excess of the market average should be viewed with suspicion and as being unrealistic and may lead to overestimation of available capital with the possibility of default. For example, if the average borrower has a risk corresponding to a volatility of $10 \%$, it is unlikely that a bank would even consider originating a loan to someone with a risk 3 times greater, since such a borrower would most likely not repay the debt. Should the borrower with higher risk offer proportionately higher reward for the loan the bank should continue to refuse to originate the loan due to an unreasonably high risk of default. Similarly, in periods preceding financial crisis we observe (see accompanying chart) that banks experienced high levels in the rate-ofreturn to volatility ratio, ultimately leading to default.

Current values of the measures calculated using the NASDAQ Bank Index and presented in the accompanying chart, indicate a high probability of crisis development since, historically, when rate-of-return and rate-of-return to volatility ratio are negative (here -0.7 and -0.3 , respectively) and when volatility is unusually large (here about $30 \%$ ), crisis is imminent.

If the volatility indicator was used alone, we might claim that the crisis is already upon us. This is not the case. We propose a probability model (a derivative of the True Skill Model) that integrates all three of these indicators, simultaneously, to obtain a more accurate estimate of crisis proximity. The "True Skill" model (Herbrich et al. 2007) can be used to compare and match "teams" or "players", using the probability of a draw. Our derivation uses a draw probability of indicators in two different sectors - banks and companies - to understand when a draw is unlikely between two "teams" (banks versus enterprises) and hence, one "team" has an inexplicable advantage over the other. Indeed, a comparative analysis of the differences in assets, net income, ROE or shareholder equity, may demonstrate certain patterns prior to or following a financial crisis. The draw probabilities show a "distance" between two competitors and could possibly reveal a dominant "player". For example, if the ROE for banks in any year is higher than the ROE for companies, on average, we may conclude that the performance of banks exceeds that of the enterprises. Even more telling is the simultaneous behavior of the mean ROE and variance of the ROE. When banks experience high ROEs versus enterprises and when bank ROEs have smaller variances than that of enterprises, the draw probability will be smaller indicating a significant advantage to banks for that given year.

Our draw probability, then, for a competition between two "players" at any point in time can be described as follows: 


$$
\delta\left(A_{,} \mu_{M}{ }^{t}, \sigma_{M}^{t}, \beta\right)=\frac{L\left(0 \mid A^{T}{ }_{,} \mu_{M}{ }^{t}, A^{T}\left(\beta^{2} I+\sigma_{M}^{t}\right)\right)}{L\left(0 \mid 0, \beta^{2} A^{T} A\right)}
$$

Since there are only two categories of competitors, we assume that both banks and enterprises are competing with each other in terms of ROE, Shareholder Equity and so forth. The $\boldsymbol{\mu}_{\boldsymbol{M}}$ in the equation above, represents a mean vector for the various indicators calculated for both banks and enterprises, $\boldsymbol{\sigma}_{\boldsymbol{M}}^{t}$ represents the variance matrix of the two indicators. Finally, since we consider only one indicator for banks and enterprises at a time, $\boldsymbol{A}$ is the matrix of assignment and would be simply $(1,-1)$.

Based upon the historical data, we conclude that the logistic distribution would be the best representation of draw probability at time $t$ and takes the following form:

$$
\delta(\eta, \sigma, \beta, t)=\sqrt{\frac{2 \beta_{t}^{2}}{2 \beta_{t}^{2}+\sigma_{\text {bank,t }}^{2}+\sigma_{\text {company,t }}^{2}}} \frac{4 e^{\eta\left(\mu_{,} \sigma_{0}, \beta_{t} t\right)}}{\left(1+e^{\eta\left(\mu_{i} \sigma_{,} \beta_{t} t\right)}\right)^{2}}
$$

where $\eta$ equals:

$$
(\mu, \sigma, \beta, t)=\frac{\mu_{\text {bank }}^{t}-\mu_{\text {company }}^{t}}{\sqrt{\frac{3}{\pi^{2}}\left(2 \beta_{t}^{2}+\sigma_{\text {bank }, t}^{2}+\sigma_{\text {company,t }}^{2}\right)}}
$$

\section{Research Methodology and Results}

We have examined financial report data (profit and loss statement and balance sheet), for banks and enterprises from the Wharton database. Data analyzed derive from the period between 1959-2010, but due to low numbers in the bank sample during the period up to 1969 we can interpret results commencing from 1970. The bank-sample consists of 30 entities in 1970 up to 800 in 1994 and currently in years 2009-2010, the number is around 500. The enterprise-sample consists of 1700 entities in 1970 up to 7000 in 1996 and currently in years 2009-2010, around 4500. Our primary hypothesis maintains that the banks' funds, allocated to projects in the real economy, cannot yield returns which consistently exceed those realized by the borrowing enterprises and that the risk shared between the banking and enterprise sectors cannot be, on average, extremely disproportional.

In Figure 2, we show mean differences in ROE, differences in the standard deviations ROE and draw probabilities for Banks versus Enterprises. There are clear deviations from the "average trend line" in these graphics which appear to be associated with impending economic/financial crisis. And, the magnitudes of those deviations seem to be correlated with the magnitude of the financial crisis? Notice too that prior to some of the most severe financial crises, the draw probabilities approach a value of 1, indicating that banks have lost their advantage, suggesting an increased tolerance for risk in the enterprise sector. Finally, deviations from the normal trend for draw probabilities are very much correlated with deviations from 
the normal trends in differences in both standard deviations and means. This result is consistent, again, with the notion that banks have lost their advantage and/or that enterprises have increased tolerance for risk (likely unhealthy risk).

Figure 2. Mean Differences in ROE, Differences in the Standard Deviations ROE and Draw Probabilities for Banks versus Enterprises

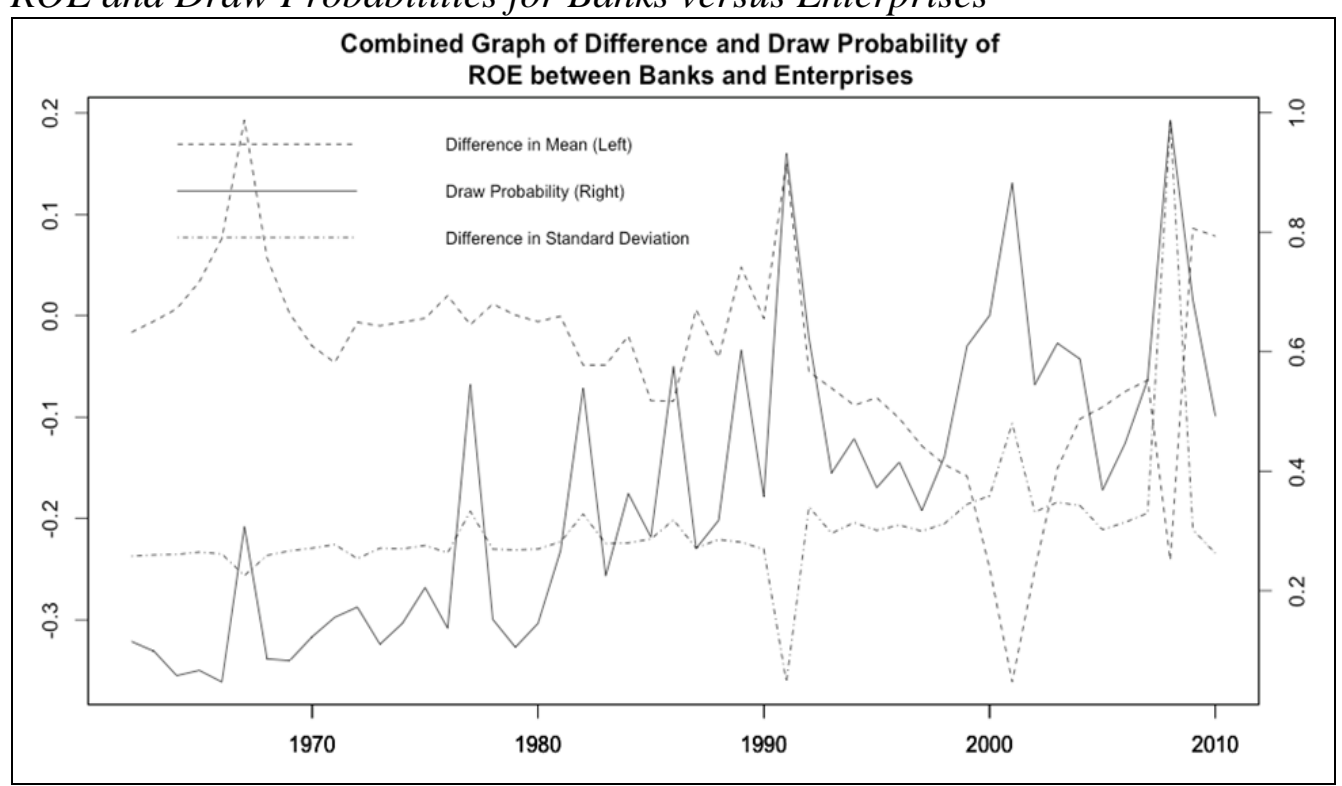

Source: Authors' estimations.

\section{Conclusions}

Banks and financial institutions hold a substantial portion of national assets (banks assets in USA around \$15 Trillion, roughly equal to the annual GDP) suggesting that any risk associated with transactions between enterprises and financial sector (primarily banks) can have marked impact on the value of enterprise and the economy as well.

Since 1996, we have observed unusual disproportion in risk and return measures between the banking and enterprise sectors. This growing asymmetry in risk indicates a potential threat of financial distress. We believe that using the indicators identified in this paper to monitor the risk on micro and macro levels, we might avoid the severe consequences of a major crisis (mitigating the possibly devastating outcomes) and limit the result to what might be considered a "regular" recession?

The crisis case-study delivers much knowledge about its mechanisms on a microeconomic level but there is little knowledge from a macroeconomic perspective. Predicting financial crisis is very difficult when based only on technical analysis and the usual assumptions about the rationality of market "players". Whilst these tools are useful, we think that it may be possible to collect more evidence about crisis proximity if a study is extended to include analysis of risk allocation across the economic entities and sectors. 


\section{References}

Claessens SM, Ayhan Kose M, Terrones ME (2011) Financial Cycles: What? How? When. IMF Working Paper. Retrieved from http://goo.gl/ndc9Oy.

Darrell D (2011) How Big Banks Fail. New Jersey: Princeton University Press.

Herbrich R, Minka T, Graepel T (2007) TrueSkill (tm): a bayesian skill rating system. In B Scholkopf, J Platt, T Hoffman (Eds.). Advances In Neural Information Processing Systems 19: 569-576. Cambridge, MA: MIT Press.

Jajuga K, Krysiak Z (2005) Credit Risk of Mortgage Loans - Modeling and Management. Polish Bank Association.

Mendoza EG, Terrones ME (2012) An anatomy of credit booms and their demise. NBER. Working Paper No. 18379 (September).

Smith M, Michaelson J (2006) Business Survival Skills. Graziadio Business Review 9(2).

Williams MT (2010) Uncontrolled Risk: The Lessons of Lehman Brothers and how Systemic Risk Can Still Bring Down the World Financial System. New York: McGraw Hill.

Wright RE (2010) Bailouts: Public Money, Private Profit. New York: Columbia University. 
